\title{
Enhancement of Electron Transfer Efficiency in Solar Cells Based on PbS QD/N719 Dye Cosensitizers
}

\author{
Yanyan Gao, Xiaoping Zou, Zhe Sun, Zongbo Huang, and Hongquan Zhou \\ Beijing Key Laboratory for Sensor, Ministry-of-Education Key Laboratory for Modern Measurement and Control Technology and \\ School of Applied Sciences, Beijing Information Science and Technology University, Jianxiangqiao Campus, Beijing 100101, China
}

Correspondence should be addressed to Xiaoping Zou,xpzou2005@gmail.com

Received 20 June 2012; Accepted 26 June 2012

Academic Editor: Jiaguo Yu

Copyright (๑) 2012 Yanyan Gao et al. This is an open access article distributed under the Creative Commons Attribution License, which permits unrestricted use, distribution, and reproduction in any medium, provided the original work is properly cited.

\begin{abstract}
Cosensitized solar cells (CSSCs) have recently become an active subject in the field of sensitized solar cells (SSCs) due to their increasing electronic utilization. However, because of the dye molecules, layer must be single, dye-SSCs cannot be co-sensitized with two different dyes to form two different molecules layer. But it is possible to be cosensitized with quantum dots (QDs) and dyes. Here we designed novel photoanode architecture, namely, PbS QDs and N719 dyes are used as co-sensitizers of the TiO 2 mesoporous film. The experimental result shows that PbS QDs/N719 dyes co-sensitized structure can make PbS QDs and N719 dyes mutual improvement. Taking the advantage of $\mathrm{PbS}$ not only achieved higher transfer efficiency of photo-excited electron, but also achieved obviously wider range and higher intensity of absorption. The $\mathrm{PbS}$ QDs which have been deposited on the $\mathrm{TiO}_{2}$ film was coated by N719 dyes, which can effectively prevent PbS QDs from corroding by $\mathrm{I}^{-} / \mathrm{I}_{3}^{-}$electrolyte and light. As we expected, the solar energy-conversion efficiency which is showed by CSSCs fabricated following these photoanodes is relatively higher than the PbS QDs or N719 dyes, single-sensitized solar cells under the illumination of one sun.
\end{abstract}

\section{Introduction}

Quantum dots-sensitized solar cells (QDSSCs) and dyesensitized solar cells (DSSCs) have attracted more and more interest due to their characteristics of low cost, surrounding friendly and high energy-conversion efficiency than the conventional silicon-based solar cell. The electrode of DSSCs usually includes a mesoporous oxide layer (such as $\mathrm{TiO}_{2}$, $\mathrm{ZnO}$, and $\mathrm{SnO}_{2}$ ) and a single molecular dye layer [1]. The dyes on the surface of the mesoporous oxide film play a role in increasing the optical activity of electrode in visible light region $[1,2]$. In addition to the organic sensitizers, semiconductor quantum dots (QDs), such as CdS [3-7], CdSe [7-10], PbS [11-13], and ZnSe [14] which absorb light in the visible region, can also serve as sensitizers of DSSCs, that is, QDSSCs [15]. The specific advantages of QDs over organic materials in light harvest come from the quantum confinement effect [16]. Although, the maximum efficiency theoretically predicted for a DQSSCs is higher than that for DSSCs using organic sensitizers. But now their energy conversion is lower than DSSCs.
So as to extend absorption range and increase conversion efficiency, cosensitization has been used in QDSSCs. QDSSc constructed with Mn-doped CdS/CdSe co-sensitized delivered highest power conversion efficiency of $5.4 \%$ by Santra et al. prepared [17]. Lee and Lo have also prepared QDSSCs cosensitization of CdS/CdSe which showed the higher conversion efficiency (4.22\%) [7]. Lee et al. have prepared QDSSCs based on CdSe and Mg-doped CdSe nanocrystals which also showed higher performance than that of single-sensitized solar cell [18]. However, because of the single dye molecules, layer must be single, DSSCs cannot be co-sensitized with two different dyes forming two different molecules layers. But it is impossible to be co-sensitized with quantum dots and dyes.

The unique property of $\mathrm{PbS}$ can effectively inhibit the charge recombination, which is different from other semiconductors $[19,20]$. Taking this advantage of $\mathrm{PbS}$, the novel electrode structure based on PbS QDs/N719 dyes co-sensitization is prepared. It is the main purpose to enhance the transfer efficiency of photoexcited electron, meanwhile, extend absorption range and increase absorption 
intensity. Firstly, $\mathrm{PbS}$ nanoparticles are deposited on the $\mathrm{TiO}_{2}$ mesoporous film using screen printing by SILAR method. Then, the $\mathrm{PbS} \mathrm{QDs} / \mathrm{TiO}_{2}$ mesoporous film is immersed in N719 dyes. In this work, taking the advantage of PbS not only achieves higher transfer efficiency of photoexcited electron, but also achieves wider range and higher intensity of absorption obviously. The PbS QDs which have been deposited on the $\mathrm{TiO}_{2}$ film were coated by N719 dyes, which can effectively prevent $\mathrm{PbS}$ QDs from corroding by $\mathrm{I}^{-} / \mathrm{I}_{3}^{-}$electrolyte and light. As we expected, the solar energyconversion efficiency which is showed by CSSC fabricated following these photoanode is relatively higher than the $\mathrm{PbS}$ QDs or N719 dyes single-sensitized solar cell, under the illumination of one sun (AM 1.5, under $100 \mathrm{~mW} / \mathrm{cm}^{2}$ ).

\section{Experimental and Characterization}

$\mathrm{TiO}_{2}$ mesoporous films were prepared by screen printing of $\mathrm{TiO}_{2}$ paste on clear Fn-doped $\mathrm{SnO}_{2}$ oxide (FTO) glass substrates, which have been pretreated by being immers into $\mathrm{TiCl}_{4}$ aqueous solution and then sintered at $70^{\circ} \mathrm{C}$ for $30 \mathrm{~min}$. Followed by sintering at $450^{\circ} \mathrm{C}$ for $30 \mathrm{~min}$, successive ionic layer absorption and reaction (SILAR) method was used to assemble $\mathrm{PbS}$ QDs onto the $\mathrm{TiO}_{2}$ mesoporous film. The $\mathrm{TiO}_{2}$ film was dipped into ethanol solution containing $\mathrm{Pb}\left(\mathrm{NO}_{3}\right)_{2}(0.1 \mathrm{M} / \mathrm{L})$ which was precursor solution of $\mathrm{Pb}^{2+}$ for $60 \mathrm{~s}$, rinsed with ethanol (then dried with Nitrogen), and dipped another $60 \mathrm{~s}$ in the $\mathrm{Na}_{2} \mathrm{~S}(0.1 \mathrm{M} / \mathrm{L})$ methanol solution which was precursor solution of $S^{2-}$ and rinsed again with methanol (then dried with nitrogen), which was one SILAR cycles. Then, the $\mathrm{TiO}_{2}$ film which have been coated by PbS QDs was immersed into N719 dyes paste for $44 \mathrm{~h}$. The preparation of photoanode was completed.

The counter electrodes were Pt-coated FTO glasses. $0.1 \mathrm{M}$ LiI, $0.05 \mathrm{M} \mathrm{I}_{2}, 0.6 \mathrm{M}$ 1,2-dimethyl-3-piopylimidazole iodide (DMP II), and 0.5 M 4-tert-butylpyridine are dissolved into 3-methoxypropionitrile solution used as electrolyte. The active area of the sensitized solar cell is $0.4 \times 0.4 \mathrm{~cm}^{2}$ and the reaction temperature is room temperature (about $27^{\circ} \mathrm{C}$ ).

A field-emission gun scanning electron microscope (SEM, QUANTA 200) with an energy dispersive X-ray spectroscopy (EDS) system was used to characterize the morphology and composition of the samples. Energy dispersive X-ray spectroscopy (EDS) image was recorded by energy dispersive X-ray spectroscopy (EDS) system. The ultraviolet visible (UV-Vis) spectroscopy was recorded in the wavelength range of $350-1000 \mathrm{~nm}$ by using the Cary 5000 spectrometer (US Varian). The photocurrent-voltage $(J-V)$ curves were measured under an illumination of a solar simulator at one sun (AM1.5, $\left.100 \mathrm{mWcm}^{-2}\right)$. An Eco-Chemie Autolab potentiostat/galvanostat (Princeton Research, V3$400)$ was used to record the current-voltage $(J-V)$ curves.

\section{Results and Discussion}

In order to understand the action of PbS QDs in the $\mathrm{PbS}$ QDs/N719 dyes, co-sensitizer, the SILAR cycles which were used to deposited PbS QDs range from 0 to 3 cycles and

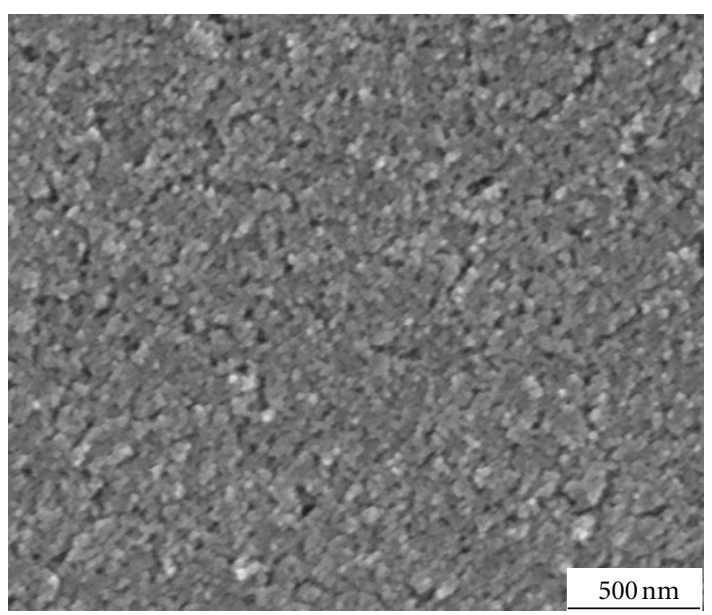

(a)

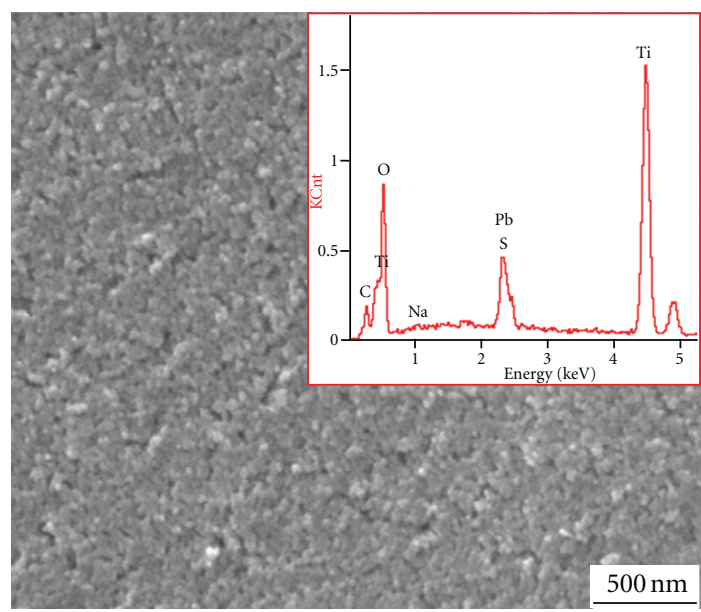

(b)

Figure 1: (a) SEM image of bare $\mathrm{TiO}_{2}$ mesoporous film and (b) SEM image of PbS QDs-coated $\mathrm{TiO}_{2}$ mesoporous film, where SILAR cycles are 2 cycles. EDX image of $\mathrm{PbS} \mathrm{QDs} / \mathrm{TiO}_{2}$ mesoporous film which is contained (b).

deposition time was 30 seconds. Samples were named as N719, 30PbS1-N719, 30PbS2-N719, and 30PbS3-N719.

For the sake of ensuring that $\mathrm{PbS}$ have assembled on the $\mathrm{TiO}_{2}$ mesoporous film before coated N719 dyes, the surface morphologies of bare $\mathrm{TiO}_{2}$ mesoporous film using screen printing and the PbS-sensitized $\mathrm{TiO}_{2}$ mesoporous film using SILAR method were characterized by SEM. The SEM images are shown in Figure 1; not very apparent difference in the surface morphology was observed from the SEM images after PdS QDs were assembled on the $\mathrm{TiO}_{2}$ film. This result indicates that particle size of $\mathrm{PbS}$ is so surprisingly small that the presence of these little particles cannot be distinguished under resolution of the SEM. But if carefully observed, we find that the mesoporous have become smaller after deposited PbS QDs. The EDS image of PbS QDs/TiO mesoporous film which is in the upper right corner of Figure 1(b) clearly indicates that PbS QDs have successfully deposited onto the $\mathrm{TiO}_{2}$ film. 
TABLE 1: Performance parameter of different SILAR cycles PbS/N719 SSCs.

\begin{tabular}{lcccc}
\hline Samples & $J_{\text {sc }}\left(\mathrm{mA} / \mathrm{cm}^{2}\right)$ & $V_{\text {oc }}(\mathrm{V})$ & FF & Eff. $(\%)$ \\
\hline N719 & 8.934 & 0.725 & 0.64 & 4.32 \\
30PbS1-N719 & 7.131 & 0.743 & 0.69 & 3.67 \\
30PbS2-N719 & 9.074 & 0.759 & 0.66 & 4.53 \\
30PbS3-N719 & 8.655 & 0.749 & 0.64 & 4.16 \\
\hline
\end{tabular}

TAble 2: Performance parameter of PbS QDs different deposition time.

\begin{tabular}{lcccc}
\hline Samples & $J_{\text {sc }}\left(\mathrm{mA} / \mathrm{cm}^{2}\right)$ & $V_{\text {oc }}(\mathrm{V})$ & FF & Eff. $(\%)$ \\
\hline N719 & 8.934 & 0.725 & 0.64 & 4.32 \\
30PbS2-N719 & 9.074 & 0.759 & 0.66 & 4.53 \\
60PbS2-N719 & 10.290 & 0.766 & 0.65 & 5.14 \\
90PbS2-N719 & 9.469 & 0.773 & 0.63 & 4.63 \\
\hline
\end{tabular}

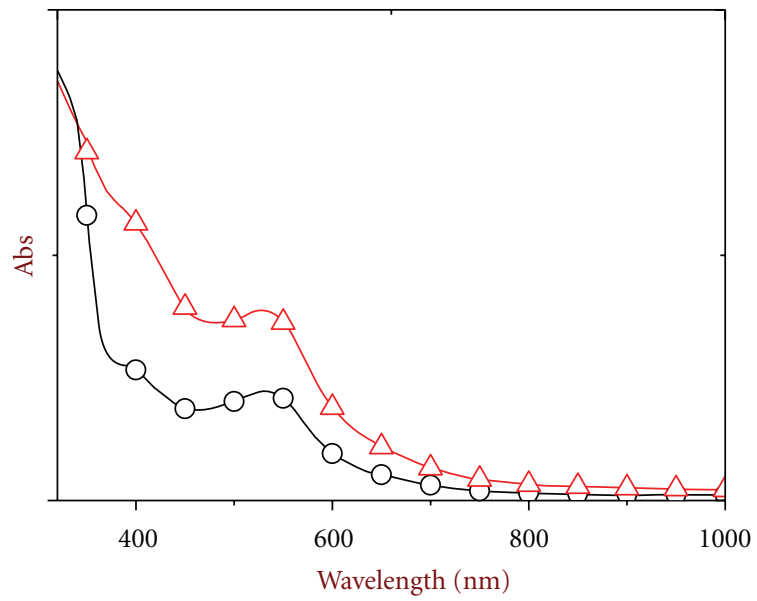

-O- N719

$-\triangle$ 30PbS2-N719

(a)

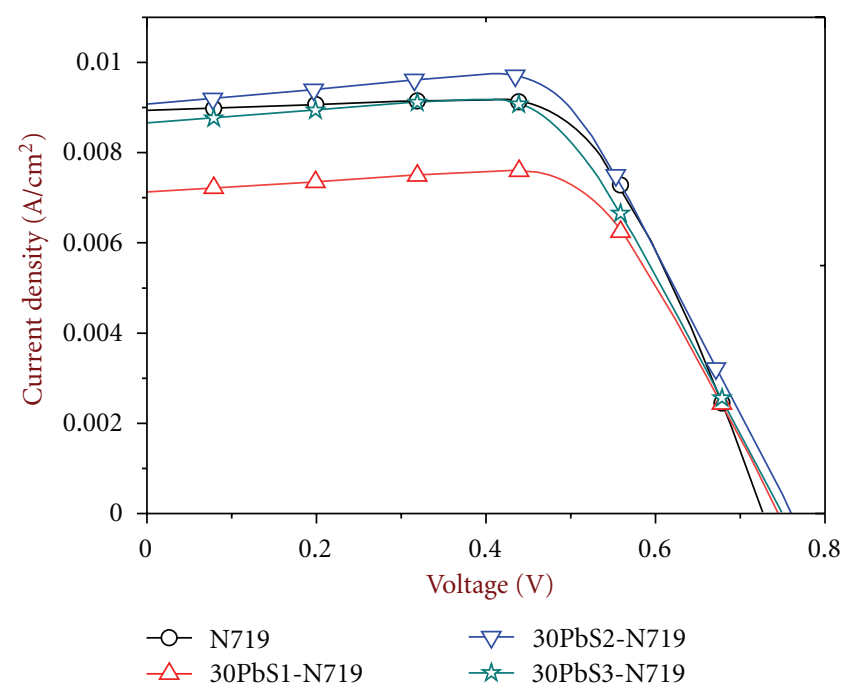

(b)

Figure 2: (a) UV-Vis spectrum and (b) $J-V$ curves of $\mathrm{PbS}$ QDs/N719 dyes co-sensitized photoanodes and N719 dyes single sensitized.
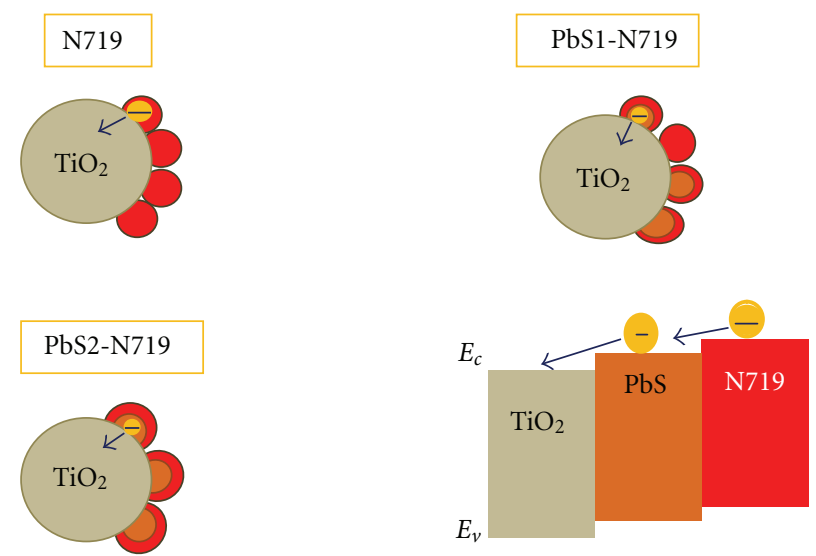

FIGURE 3: The structure and energy level of PbS QDs/N719 dyes, co-sensitized photoanodes.

By using SILAR process, $\mathrm{PbS}$ could be deposited onto the $\mathrm{TiO}_{2}$ mesoporous film and the incorporated amount of QDs is raised with increasing SILAR cycles. Then films were dipped into N719 dyes pate and can get the PbS QDs/N719 dyes co-sensitized electrode. The variation of UVvis spectrum is shown in Figure 2(a). We can observe that absorption of PbS QDs/N719 dyes, co-sensitized electrode shifts to long, wavelength range, known as red shift in the meantime, have obviously higher absorption intensity than PbS QDs or N719 dyes single sensitized. That means the PbS QDs/N719 dyes co-sensitized photoanode has an increased absorption coefficient which is advantageous to properties of Co-sensitized solar cells (CSSCs).

Those photoanodes, namely, N719, 30PbS1-N719, $30 \mathrm{PbS} 2-\mathrm{N} 719$, and 30PbS3-N719, were used to prepare SSCs. Measured $J-V$ curves are shown in Figure 2(b), responding to parameters listed in Table 1. As shown as Figure 3, PbS and N719 are brought in contact as a cascade structure and existing energy levels alignment that make conduction band levels of $\mathrm{N} 719 / \mathrm{PbS} / \mathrm{TiO}_{2}$ forming stepwise structure, which is conducive to electron transport. More importantly, PbS QDs not only can efficiently prevent electrons and holes recombination $[19,20]$, but also increase 


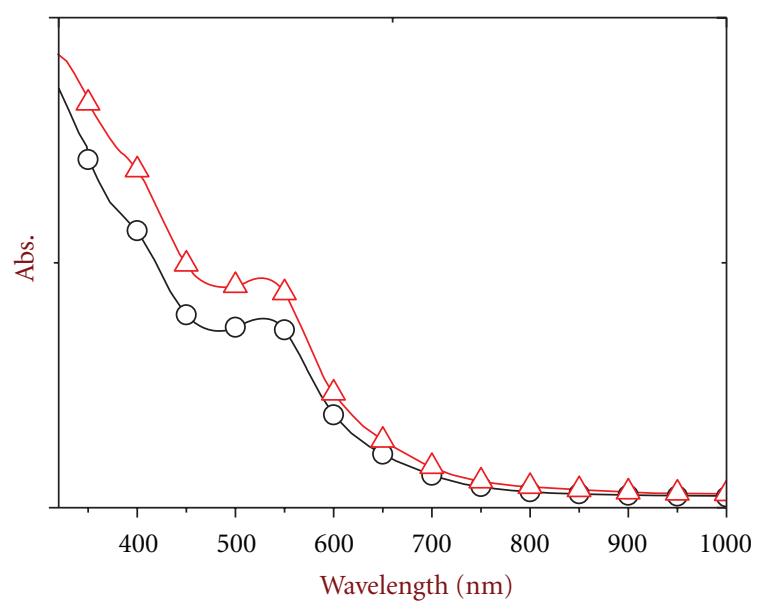

-O- 30PbS2-N719

$\triangle \quad$ 90PbS2-N719

(a)

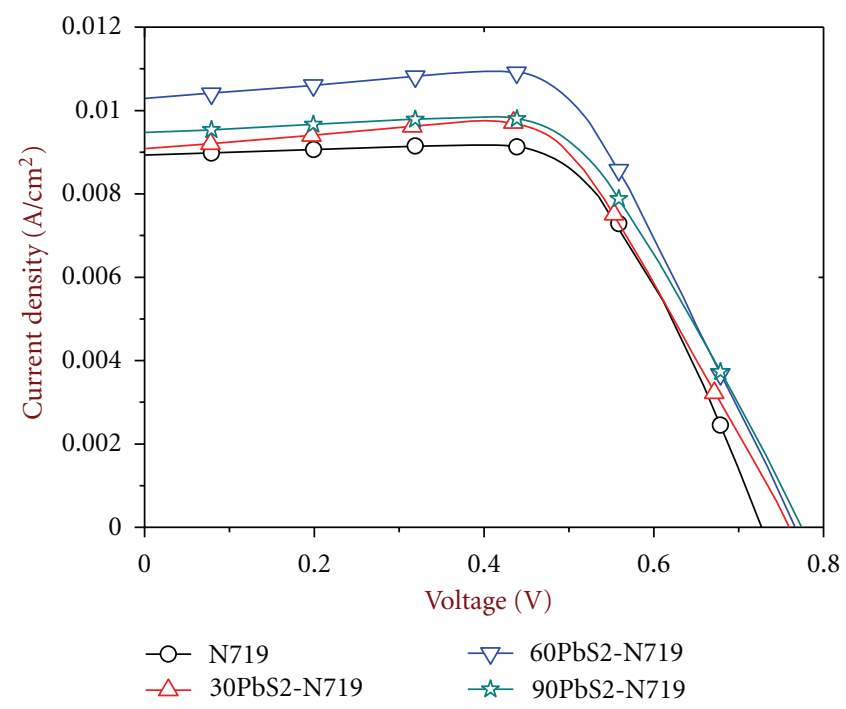

(b)

FIgURE 4: (a) UV-vis spectrum and (b) $J$ - $V$ curves of samples: N719, 30PbS2-N719, 60PbS2-N719, and 90PbS-N719.

the specific surface area where will be deposited more N719 dye molecules. Based on above superiors, a higher transfer efficiency of photoexcited electron is achieved. In addition, PbS QDs which have been coated by N719 dyes can be effectively prevented from corroding by $\mathrm{I}^{-} / \mathrm{I}_{3}^{-}$electrolyte and light. But we find that the energy conversion efficiency of 30PbS1-N719 is lower than N719. That is because the $\mathrm{PbS}$ QDs have very little effect on the specific surface area when, deposited one layer QDs, but instead make N719 dyes absorption decreased, which reduce the short-circuit current density $\left(J_{S C}\right)$. The SILAR cycles increase to 3 layers and more will increase the number and the particle size of PbS QDs, then dipped N719 dyes, which will clog the pores of $\mathrm{TiO}_{2}$ film. As a result, the difficulties of electrolyte diffuse into pores, higher recombination of photoexcited electrons, and reduction of $J_{\mathrm{SC}}$, so energy that conversion efficiency (Eff.) of 30PbS3-N719 is lower than of 30PbS2-N719.

To achieve a better result, we tailored the deposition time of SILAR cycles to control particle size of PbS QDs. The PbS deposition SILAR cycles were all 2 layers, the deposition time is $0 \mathrm{~S}, 30 \mathrm{~S}, 60 \mathrm{~S}$, and $90 \mathrm{~S}$, respectively. Samples are named as N719, 30PbS2-N719, 60PbS2-N719, and 90PbS-N719.

From Figure 4 and Table 2, we find that the increase in deposition time will raise $J_{\mathrm{SC}}$, open-circle voltage $\left(V_{\mathrm{oc}}\right)$, and energy, conversion efficiency. The best deposition time of PbS using SILAR method is $60 \mathrm{~s}$ an energy conversion efficiency of $5.14 \%$ is achieved. Continue to increase the time, the $J_{\mathrm{SC}}, V_{\mathrm{oc}}$, and Eff. will reduce. Because particle size of $\mathrm{PbS}$ QDs will become too larg to clog the small mesoporous after dipped N719 dyes, this is like 30PbS3-N719.

\section{Conclusion}

The PbS QDs/N719 dyes co-sensitized photoanode as the work electrode of SSCs is better than, PbS QDs or N719 dye, single-sensitized photoanodes. PbS QDs/N719 dyes cosensitized structure can make PbS QDs and N719 dyes mutualy improved. Taking the advantage of $\mathrm{PbS}$ not only achieved higher transfer efficiency of photoexcited electron, but also achieved obviously wider range and higher intensity of absorption. The PbS QDs which have been deposited on the $\mathrm{TiO}_{2}$ film were coated by N719 dyes, which can effectively prevent $\mathrm{PbS}$ QDs from corroding by $\mathrm{I}^{-} / \mathrm{I}_{3}^{-}$electrolyte and light. The solar energy-conversion efficiency which is showed by CSSC fabricated following PbS QDs/N719 dyes cosensitized photoanode is relatively higher than the $\mathrm{PbS}$ QDs or N719 dyes single-sensitized solar cell, under the illumination of one sun.

\section{Acknowledgments}

This work was partially supported by the Key Project (B) of Beijing Natural Science Foundation and the Key Project of Beijing Education Committee Science \& Technology Plan (KZ201211232040), the State High Technology Research and Development Plan (863 Plan) of the Ministry of Science and Technology of China (2011AA050527), the State Key Laboratory of Advanced technology for Materials Synthesis and Processing of the Wuhan University of Technology (2012-KF-6), State Key Laboratory of Fine Chemicals of the Dalian University of Technology (KF1016), the State Key Laboratory of Multiphase Complex Systems of the Institute of Process Engineering of CAS (MPCS-2011-D09 and MPCS-2010-A-02), the Key Lab of Photochemical Conversion and Optoelectronic Materials of TIPC of CAS (PCOM201111 and PCOM201211), the Key Lab of Novel Thin Film Solar Cells of CAS (KF200907), the Key Laboratory of Semiconductor Materials Science of the Institute of Semiconductors of CAS (KLSMS-1101), and the Beijing Key Laboratory for sensor (KF20121077206). 


\section{References}

[1] M. Grätzel, "Photoelectrochemical cells," Nature, vol. 414, no. 6861, pp. 338-344, 2001.

[2] E. Joanni, R. Savu, M. de Sousa Góes et al., "Dye-sensitized solar cell architecture based on indium-tin oxide nanowires coated with titanium dioxide," Scripta Materialia, vol. 57, no. 3, pp. 277-280, 2007.

[3] W.-T. Sun, A. Yu, H.-Y. Pan, X.-F. Gao, Q. Chen, and L.M. Peng, "CdS quantum dots sensitized $\mathrm{TiO}_{2}$ nanotube-array photoelectrodes," Journal of the American Chemical Society, vol. 130, no. 4, pp. 1124-1125, 2008.

[4] Y.-L. Lee and C.-H. Chang, "Efficient polysulfide electrolyte for CdS quantum dot-sensitized solar cells," Journal of Power Sources, vol. 185, no. 1, pp. 584-588, 2008.

[5] C.-H. Chang and Y.-L. Lee, "Chemical bath deposition of CdS quantum dots onto mesoscopic $\mathrm{TiO}_{2}$ films for application in quantum-dot-sensitized solar cells," Applied Physics Letters, vol. 91, no. 5, Article ID 053503, 2007.

[6] W. Lee, S. K. Min, V. Dhas, S. B. Ogale, and S.-H. Han, "Chemical bath deposition of CdS quantum dots on vertically aligned $\mathrm{ZnO}$ nanorods for quantum dots-sensitized solar cells," Electrochemistry Communications, vol. 11, no. 1, pp. 103-106, 2009.

[7] Y.-L. Lee and Y.-S. Lo, "Highly efficient quantum-dotsensitized solar cell based on co-sensitization of CdS/CdSe," Advanced Functional Materials, vol. 19, no. 4, pp. 604-609, 2009.

[8] S.-Q. Fan, D. Kim, J.-J. Kim, D. W. Jung, S. O. Kang, and J. Ko, "Highly efficient CdSe quantum-dot-sensitized $\mathrm{TiO}_{2}$ photoelectrodes for solar cell applications," Electrochemistry Communications, vol. 11, no. 6, pp. 1337-1339, 2009.

[9] J. Chen, D. W. Zhao, J. L. Song et al., "Directly assembled CdSe quantum dots on $\mathrm{TiO}_{2}$ in aqueous solution by adjusting $\mathrm{pH}$ value for quantum dot sensitized solar cells," Electrochemistry Communications, vol. 11, no. 12, pp. 2265-2267, 2009.

[10] Q. Shen, T. Sato, and M. Hashimoto, "Photoacoustic and photo electrochemical characterization of CdSe-sensitized TiO2 electrodes composed of nanotubes and nanowires," Thin Solid Films, vol. 499, pp. 299-305, 2006.

[11] W. Lee, J. Lee, S. K. Min, T. Park, W. Yi, and S.-H. Han, "Effect of single-walled carbon nanotube in $\mathrm{PbS} / \mathrm{TiO}_{2}$ quantum dotssensitized solar cells," Materials Science and Engineering B, vol. 156, no. 1-3, pp. 48-51, 2009.

[12] R. Plass, S. Pelet, J. Krueger, M. Grätzel, and U. Bach, "Quantum dot sensitization of organic-inorganic hybrid solar cells," Journal of Physical Chemistry B, vol. 106, no. 31, pp. 7578-7580, 2002.

[13] P. Hoyer and R. Könenkamp, "Photoconduction in porous $\mathrm{TiO}_{2}$ sensitized by $\mathrm{PbS}$ quantum dots," Applied Physics Letters, vol. 66, pp. 349-351, 1995.

[14] D. H. Kim, Y. H. Lee, D. U. Lee, T. W. Kim, S. Kim, and S. W. Kim, "Significant enhancement of the power conversion efficiency for organic photovoltaic cells due to a P3HT pillar layer containing ZnSe quantum dots," Optics Express, vol. 20, no. 10, pp. 10476-10483, 2012.

[15] Y. L. Lee, B. M. Huang, and H. T. Chien, "Highly efficient CdSe-sensitized $\mathrm{TiO}_{2}$ photoelectrode for quantum-dotsensitized solar cell applications," Chemistry of Materials, vol. 20, no. 22, pp. 6903-6905, 2008.

[16] Y. Wang and N. Herron, "Nanometer-sized semiconductor clusters: materials synthesis, quantum size effects, and photophysical properties," Journal of Physical Chemistry, vol. 95, no. 2, pp. 525-532, 1991.
[17] P. K. Santra and P. V. Kamat, "Mn-doped quantum dot sensitized solar cells: a strategy to boost efficiency over 5\%," Journal of the American Chemical Society, vol. 134, no. 5, pp. 2508-2511, 2012.

[18] W. Lee, W. C. Kwak, S. K. Min et al., "Spectral broadening in quantum dots-sensitized photoelectrochemical solar cells based on CdSe and Mg-doped CdSe nanocrystals," Electrochemistry Communications, vol. 10, no. 11, pp. 1699-1702, 2008.

[19] R. J. Ellingson, M. C. Beard, J. C. Johnson et al., "Highly efficient multiple exciton generation in colloidal $\mathrm{PbSe}$ and $\mathrm{PbS}$ quantum dots," Nano Letters, vol. 5, no. 5, pp. 865-871, 2005.

[20] A. J. Nozik, "Exciton multiplication and relaxation dynamics in quantum dots: applications to ultrahigh-efficiency solar photon conversion," Inorganic Chemistry, vol. 44, no. 20, pp. 6893-6899, 2005. 

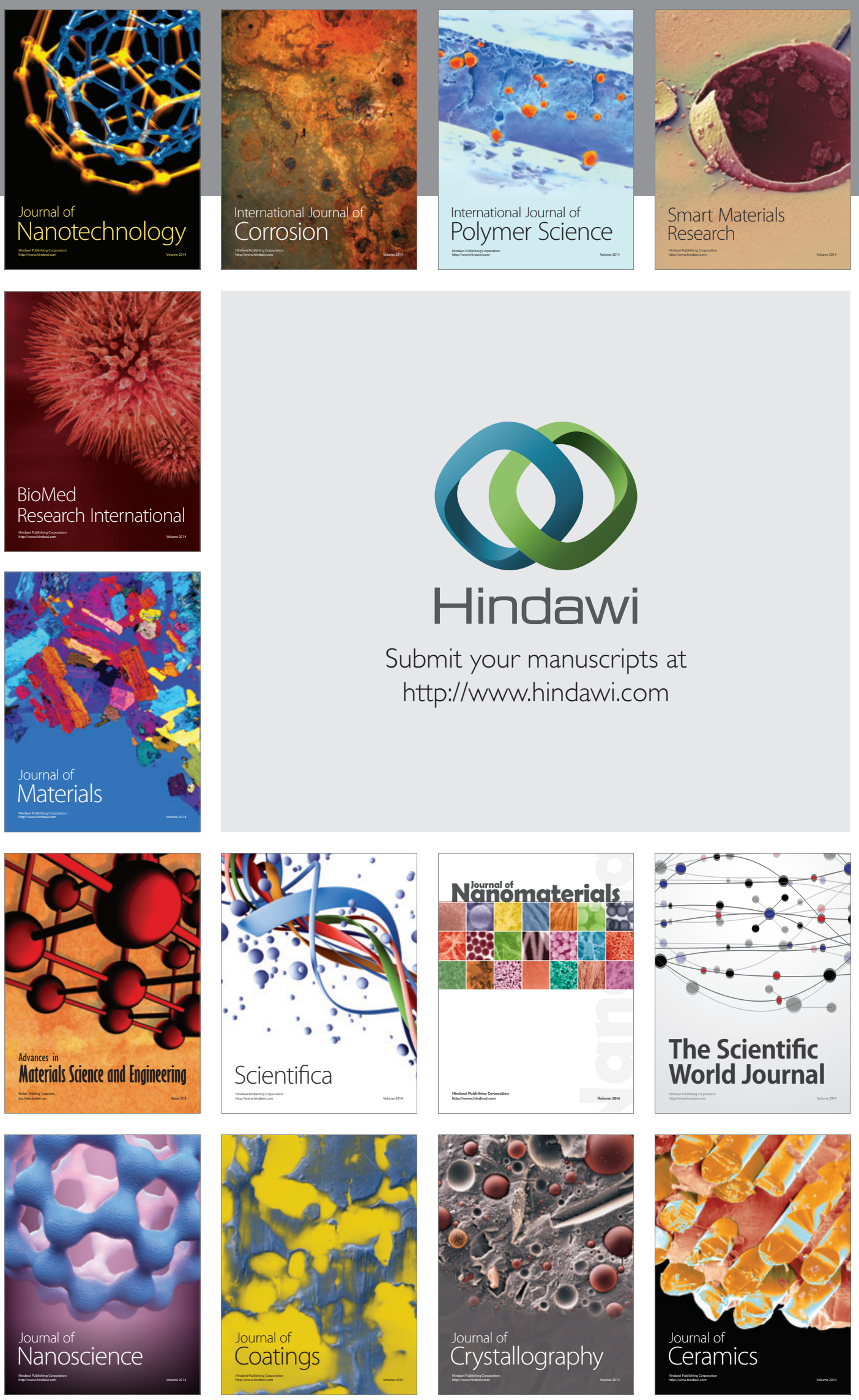

The Scientific World Journal

Submit your manuscripts at

http://www.hindawi.com

\section{World Journal}

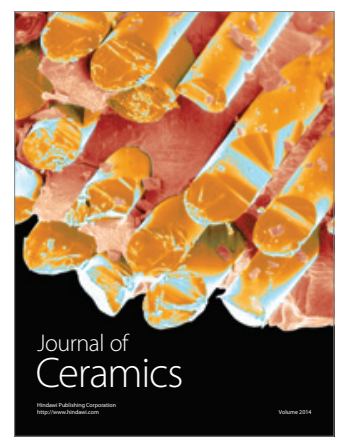

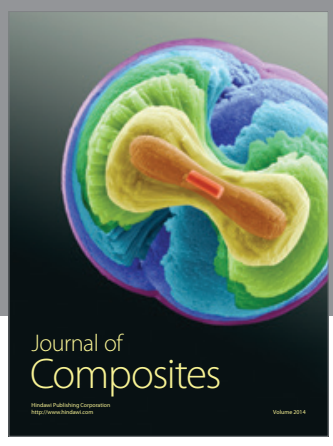
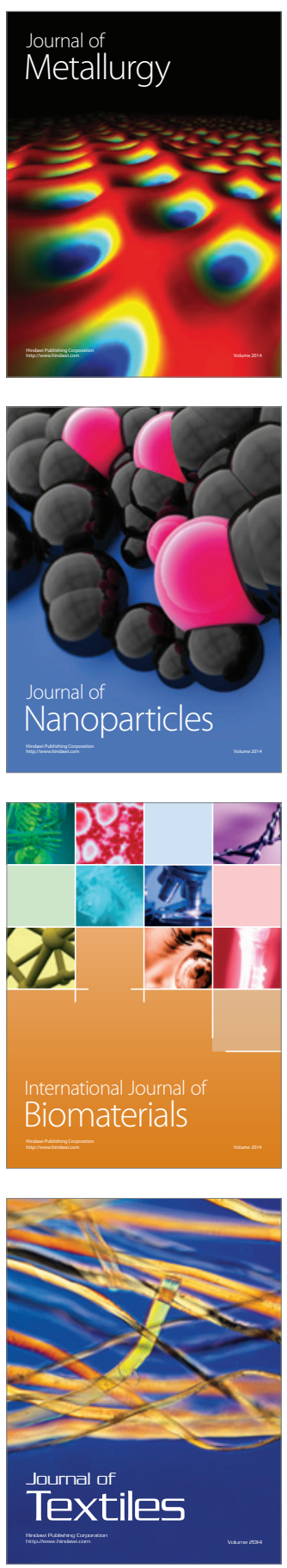